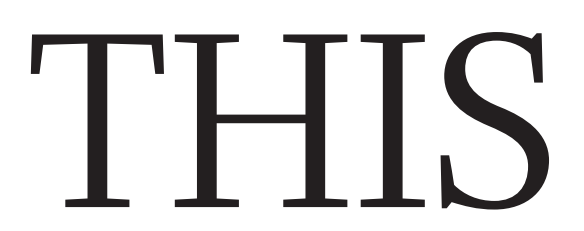

EDITORIALS
ANNOUNCEMENT A bid to stamp out the use of contaminated cell lines p.264

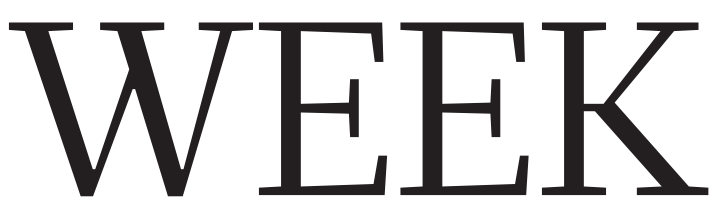

\title{
Close the deal
}

\section{Science-based evidence and enlightened diplomacy have brought within reach a historic opportunity for nuclear détente with Iran. It must be seized.}

$\mathrm{I}$ $\mathrm{n}$ a diplomatic tour de force, negotiators from six world powers and Iran reached - against the odds - a tentative agreement on 2 April to ensure that Iran's nuclear programme is for peaceful purposes only. It is science-informed diplomacy and foreign policy at its best. Even the most optimistic of seasoned nuclear-weapons and non-proliferation experts were surprised by the comprehensiveness of the interim accord, its level of detail, and the substantial concessions made on both sides. Few had expected this degree of progress given the decades of hostility and intransigence on both sides.

In a perhaps unprecedented flurry of published opinion pieces and statements, experts have overwhelmingly lent their support to the accord. They have also subjected it to robust online peer review, highlighting the positive outcomes, but also pointing out the technical loopholes and details that they feel must still be negotiated or clarified before the 30 June deadline for a final agreement.

The emphasis on getting the scientific and technical assessments that underpin the issues right, to offer political leaders confidence in the projected outcomes, has played a central part in getting to this crucial juncture. Two physicists, both at the Massachusetts Institute of Technology in Cambridge in the 1970s, had key roles: Ali Akbar Salehi, head of Iran's Atomic Energy Organization, and Ernest Moniz, the US energy secretary. In long face-to-face discussions, the men thrashed out the complex nuclear science to come up with acceptable compromises that did not cross the red lines of either side. Importantly, the lead negotiators, US secretary of state John Kerry and Iranian foreign minister Mohammad Javad Zarif, have taken on board their scientific advice.

Scientists share a language, culture and values that can help to transcend politics and enmity. Researchers involved in past nuclear-weapons treaties say that scientific collaboration between adversaries is crucial to building trust and confidence, but they emphasize that it takes time. Iran has been ostracized by many governments for almost four decades, and rebuilding trust on both sides will take years. That this rapprochement is now under way can only be commended - especially at this time of exceptional political instability in the Middle East, which has unexpectedly aligned some of Iran's and the West's strategic interests. Any easing of the sanctions on Iran and its political isolation will also benefit the country's isolated scientific community.

Experts are unanimous that the framework of the deal shows that it could essentially put Iran's nuclear programme on ice for well over a decade - and so buy the time needed to build greater trust and to develop further measures to ensure that any eventual larger Iranian nuclear programme remains peaceful. The accord would, for example, block Iran's potential route to a plutonium bomb, by redesigning the country's Arak heavy-water reactor to make it much less capable of producing weapons-grade plutonium. Moreover, all plutoniumcontaining spent fuel would be shipped out of the country.

Iran's potential to make a bomb using enriched uranium would also be curtailed to the extent judged necessary by scientists to ensure that, for the foreseeable future, it would take the country more than a year to 'break out' and develop a nuclear weapon, leaving enough time for international intervention (see page 274). The Vienna-based International Atomic Energy Agency would also be given unprecedented powers to inspect Iran's entire nuclear "Scientistsshare programme for 25 years to ensure that, were a language, Iran to violate the agreement either overtly culture and or covertly, this would be detected quickly.

values that can help to transcend politics."

Iranian and other scientists emphasize the interplay of science and politics. The breakthrough was made possible, they say, only by the election of the relative reformer Hassan Rouhani to the Iranian presidency in 2013 and of Barack Obama to the US presidency in 2008. Both leaders have been more open to pragmatic and constructive dialogue between the two nations than their predecessors. Critics of the deal have yet to put forward any credible alternatives, or any substantive challenges to its technical underpinnings, relying rather on political rhetoric and stoking fear to justify inaction. The late US president Ronald Reagan famously adopted the Russian proverb "Trust, but verify" with respect to the monitoring of nuclear-disarmament treaties with the Soviet Union. It is time once again for progressive policies to prevail over dangerous inaction.

\section{Numbers matter}

\section{Researchers need help in making the statistical power of animal experiments clear.}

A lbert Einstein is said to have noted that theories should be as simple as possible, but no simpler. By the same token, biomedical researchers doing in vivo experiments should use as few animals as possible, but no fewer. On page 271, Nature reports a move by UK government funding agencies to require grant applicants to show how they calculated the number of animals needed to make the results of an experiment statistically robust. In recent years there have been concerns that sample sizes in individual experiments can be too low, especially in preclinical research that attempts to determine whether a drug is worth pursuing in human studies.

Too-small sample sizes can lead to promising drugs being discarded when their effectiveness is missed, or to false positives, as well as to ethical issues if animals are being used in studies that are too small to provide reliable results.

The UK research councils' move is to be applauded. And Britain is 